\title{
Rational design of novel fusion rabies glycoproteins displaying a major antigenic site of foot-and-mouth disease virus for vaccine applications
}

\author{
Ernesto Garay $^{1}$ (D) $\cdot$ Diego Fontana $^{1}$ (D) $\cdot$ Lautaro Leschiutta $^{2} \cdot$ Ricardo Kratje $^{1}$ (D) Claudio Prieto $^{2}$ (D)
}

Received: 10 August 2021 / Revised: 10 December 2021 / Accepted: 14 December 2021 / Published online: 31 December 2021

(c) The Author(s), under exclusive licence to Springer-Verlag GmbH Germany, part of Springer Nature 2021

\begin{abstract}
Chimeric virus-like particles are self-assembling structures composed of viral proteins that had been modified to incorporate sequences from different organisms, being able to trigger immune responses against the heterologous sequence. However, the identification of suitable sites for that purpose in the carrier protein is not an easy task. In this work, we describe the generation of rabies chimeric VLPs that expose a major antigenic site of foot-and-mouth disease virus (FMDV) by identifying suitable regions in rabies glycoprotein (RVG), as a proof of concept of a novel heterologous display platform for vaccine applications. To identify adequate sites for insertion of heterologous sequences without altering the correct folding of RVG, we identified regions that were evolutionally non-conserved in Lyssavirus glycoproteins and performed a structural analysis of those regions using a 3D model of RVG trimer that we generated. The heterologous sequence was inserted in three different sites within RVG sequence. In every case, it did not affect the correct folding of the protein and was surface exposed, being recognized by anti-FMDV antibodies in expressing cells as well as in the surface of VLPs. This work sets the base for the development of a heterologous antigen display platform based on rabies VLPs.
\end{abstract}

\section{Key points}

- Adequate regions for foreign epitope display in $R V G$ were found.

- G-H loop of FMDV was inserted in three regions of RVG.

- The foreign epitope was detected by specific antibodies on fusion proteins.

- G-H loop was detected on the surface of chimeric VLPs.

Keywords Rabies $\cdot$ Chimeric virus-like particle $\cdot$ Fusion protein $\cdot$ Foot-and-mouth disease virus

\section{Introduction}

Virus-like particles (VLPs) are supramolecular arrangements composed of one or more viral proteins that mimic the structure of the virus but lack the viral genome, which makes them

Diego Fontana

dfontana@fbcb.unl.edu.ar

1 UNL, CONICET, FBCB (School of Biochemistry and Biological Sciences), CBL (Biotechnological Center of Litoral), Ciudad Universitaria, Ruta Nacional 168 - Km 472.4 - C.C. 242 - (S3000ZAA), Santa Fe, Argentina

2 UNL, FBCB (School of Biochemistry and Biological Sciences), CBL (Biotechnological Center of Litoral), Ciudad Universitaria, Ruta Nacional 168 - Km 472.4 - C.C. 242 (S3000ZAA), Santa Fe, Argentina biosafe (Roldão et al. 2010; Yan et al. 2015; Mohsen et al. 2017). Because of their highly multivalent nature, they are able to crosslink B cell receptors (BCRs) very efficiently to induce potent humoral responses. Their ability to induce cellular and innate immune responses and their particulate structure and size, which facilitates their uptake by antigen presenting cells, are also key features that contribute to their high immunogenicity (Grgacic and Anderson 2006; Raghunandan 2011; Lua et al. 2014).

On the other hand, some VLPs have proven effective on developing immune responses against foreign epitopes inserted by genetic fusion to the viral proteins that compose the particle, known as chimeric VLPs (cVLPs) (Grgacic and Anderson 2006; Chackerian 2007; Roldão et al. 2010; Frietze et al. 2016; Charlton Hume et al. 2019). This strategy presents however a number of difficulties: the presence of the epitope 
(most commonly a short peptide derived from a foreign organism) must not disrupt the formation of the VLPs, and it must be exposed on the surface on the particle in order to be available to interact with BCRs and with a correct antigenic conformation. All these factors lead to the need of a profound knowledge of the structural characteristics of the viral proteins integrating the VLPs, so that the foreign epitope does not alter the correct folding as well as not impairing the intermolecular interactions between the proteins that compose the particle.

Most of the efforts in this direction take advantage of the crystalized and resolved structures of empty capsid VLPs, such as hepatitis B core particle (Clarke et al. 1987; Zhang et al. 2007; Aston-Deaville et al. 2020), porcine circovirus type 2 (Hu et al. 2016; Li et al. 2018), hamster polyomavirus (Gedvilaite et al. 2000), primate erythroparvovirus 1 (del Carmen Morán-García et al. 2016), and human enterovirus 71 (Xu et al. 2015). Despite their effectivity to induce immune responses against the heterologous epitope, their ability to present a variety of structures is restrained by their rigid nature, limiting the size of the heterologous peptide that can be incorporated into the particle and often impairing VLPs assembly (Hu et al. 2016; Li et al. 2018).

Alternatively, foreign epitope display on enveloped VLPs is a field that has not been largely exploited, mostly because of the limited amount of information available on transmembrane and membrane-associated viral proteins structures. So far, the most studied enveloped VLPs platform to display foreign antigens is hepatitis B surface antigen (Delpeyroux et al. 1986; Gordon et al. 1995; Vietheer et al. 2007; Beaumont et al. 2013; Ramasamy et al. 2018; Czarnota et al. 2020), which has even allowed the development of a malaria vaccine candidate that has undergone phase III clinical trials (RTS 2015). Other enveloped VLPs systems studied to display heterologous antigens are the $\mathrm{Z}$ matrix protein of Junin virus (Mareze et al. 2016) and Newcastle disease virus hemagglutinin/neuraminidase (McGinnes et al. 2010).

Rabies virus belongs to Rhabdoviridae family and Lyssavirus genus, and is the etiological agent of a zoonotic disease that causes 40.000-60.000 human deaths per year (Hampson et al. 2015; World Health Organization 2018). Its envelope glycoprotein $\mathrm{G}$ (RVG), located on the surface of the virion, is responsible of virus entry into the cell and the main target of neutralizing antibodies (NAs) during an infection (Katz et al. 2017). It is composed by an ectodomain (AA 1-440), a short transmembrane domain (AA 441-462), and a cytoplasmic tail (AA 462-505), and forms trimers on the surface of the virion (Gaudin et al. 1992). Like other glycoproteins of the Rhabdovirus family, RVG interacts with host cell receptor and changes its conformation from a prefusion state to a post-fusion state once the virus enters in the low $\mathrm{pH}$ environment of the endosome, allowing membrane fusion and liberation of the ribonucleoprotein into the cytoplasm (Roche and Gaudin 2002; Roche et al. 2007). Most of generated antibodies in the course of an immune response are directed towards a conformational epitope located on AA 34-42 and 198-200 of mature protein (antigenic site 2, a.s 2 ), comprising approximately $70 \%$ of RVG-specific antibodies. The rest is directed towards antigenic site 3 (a.s 3 ) and to a lesser extent to antigenic site 1 (a.s 1), which are located on AA 330-338 and AA 226-231, respectively. Other minor antigenic sites have been reported (Benmansour et al. 1991; Jallet et al. 1999; Buthelezi et al. 2016).

In our laboratory, we previously generated rabies VLPs (RV-VLPs) by recombinant expression of RVG in HEK293 cells. These particles are able to bud to the culture supernatant spontaneously and are continuously expressed (Fontana et al. 2014). Moreover, they are able to induce NAs on mice and protect them from intracerebral challenges with live rabies virus (Fontana et al. 2015, 2019). The main objective of this study was to analyze the ability of RV-VLPs to present foreign epitopes, through the identification of suitable insertion sites in RVG ectodomain and the generation of fusion proteins for vaccine applications.

The chosen heterologous epitope is the major antigenic site of foot-and-mouth disease virus (FMDV), member of the Picornaviridae family and Aphthovirus genus (Grubman and Baxt 2004), which is responsible for multimillion dollar loss worldwide due to animal product trade restrictions (Mahy 2005). The major antigenic site (named G-H loop) is located on VP1 capsid protein (approximately on AA 140-160 depending on the studied serotypes) and is responsible for virus entry into the cell by host cell integrin recognition and main target of NAs (Burman et al. 2006; Azuma and Yoneda 2009).

By using this model, we intent to establish a cVLPs heterologous display platform based on the highly immunogenic enveloped RV-VLPs.

\section{Materials and methods}

\section{Identification of insertion sites in rabies $\mathbf{G}$ glycoprotein}

\section{Identification of non-conserved regions in Lyssavirus genus glycoproteins}

In order to find non-conserved regions in Lyssavirus glycoproteins, 16 complete AA sequences were downloaded from the Reference Sequence (refseq) database of the National Centre for Biotechnology Information (www.ncbi.nlm.nih. gov). The refseq codes of the glycoprotein sequences downloaded are as follows: YP_009094330.1, YP_009325517.1, YP_007641395.1，YP_001285396.1，P_009091812.1, NP_478342.1, YP_001285391.1, YP_007641405.1, YP_007641400.1, YP_009094487.1, YP_009094182.1, 
YP_142353.1, YP_007641390.1, YP_009094271.1, YP_006742183.1, YP_009325415.1. A multiple alignment of these sequences and RVG (Pasteur strain, NP_056796.1) was obtained using Clustal Omega software (Sievers et al. 2011) and the result was analyzed with Jalview software (Waterhouse et al. 2009).

\section{Generation of 3D models of rabies glycoprotein trimer}

MODELLER software (Eswar et al. 2006) was used to perform the homology modeling of RVG structure, and the structure was visualized using UCSF Chimera (Pettersen et al. 2004). MatchMaker tool of UCSF Chimera was used to superimpose the individual domains of RVG post-fusion model over VSV-G structure, and the regions connecting them were modeled using MODELLER loop refinement tool. Quality of the model was assessed using Qualitative Model Energy Analysis (QMEAN, https://swissmodel. expasy.org/qmean/) (Benkert et al. 2011) and PROCHECK server (https://servicesn.mbi.ucla.edu/PROCHECK/).

\section{Vector construction}

The strategy to obtain the coding sequences for fusion proteins RVG(SI)-GH and RVG(SII)-GH consisted on generating a restriction enzyme cutting site on each of the insertion sites by PCR overlapping, and then inserting the G-H loop (A/Arg/01) coding sequence by oligonucleotide cloning.

The first step was to obtain RVG mutated coding sequences, RVG(SI) and RVG(SII), containing a BamHI restriction site on site I and site II (codons 164-165 and 184-185 of mature protein, respectively), using a previously obtained vector pLV-G (Fontana et al. 2014) as template. The first pair of primers (RVG F and SI R) (Table 1) was used to generate the first fragment, whereas the second pair (SI F and RVG R) was used to generate the second fragment. These PCR fragments were mixed equimolarly to obtain RVG(SI) coding sequence by PCR, using the pair of primers RVG F and RVG R. Similarly, to obtain RVG(SII) sequence, the third pair of primers (RVG F and SII R) and the fourth pair of primers (SII F and RVG R) were used to obtain two PCR fragments that, when mixed equally with primers RVG F and RVG R, produced the desired sequence by PCR. The generation of a BamHI sequence on the desired sites was checked by enzyme digestion and agarose gel electrophoresis. Both recombinant DNA sequences were digested with NheI and SalI and cloned on a third-generation lentiviral transference vector ( $\mathrm{pLV}$ ) digested with the same pair of enzymes, obtaining the vectors pLV-RVG(SI) and pLV-RVG(SII).

To obtain the coding sequence of G-H loop A/Arg/01 (AA 140-160 of VP1 capsid protein, GenBank accession no. AMX81584.1), the pair of primers GH F and GH R was mixed equimolarly on TE buffer and heated at $95{ }^{\circ} \mathrm{C}$ for 5 min on a water bath. Then, heat source was turned off allowing the mix to slowly cool down to room temperature. Previously obtained lentiviral vectors were BamHI digested, and the aligned oligonucleotides were directly ligated into them, as they present BamHI overhang on both sides. The obtained vectors, $\mathrm{pLV}-\mathrm{RVG}(\mathrm{SI})-\mathrm{GH}$ and $\mathrm{pLV}-\mathrm{RVG}(\mathrm{SII})-\mathrm{GH}$, were checked by DNA sequencing.

The coding sequence for the fusion protein presenting the GH loop sequence on the $\mathrm{N}$-terminal extreme of RVG (RVG(S0)-GH) was chemically synthetized (GeneUniversal) and cloned on $\mathrm{pLV}$ vector (pLV-RVG(S0)-GH), being checked by DNA sequencing.

\section{Cells, antibodies, and vaccines}

Adherent growing HEK293 cells used to package lentiviral vectors were cultured in Dulbecco modified Eagle medium (DMEM, Gibco) supplemented with $10 \%$ fetal calf serum (FCS, Gibco) at $37{ }^{\circ} \mathrm{C}$ with 5\% CO2. In-house developed suspension growth adapted HEK293 cells (sHEK) used to generate stable cell lines were cultured in EX-CELL $® 293$ serum-free medium (SAFC Bioscience) supplemented with
Table 1 Primers used to mutate RVG coding sequence. Restriction enzyme cutting sites are marked in bold and underlined

\begin{tabular}{lll}
\hline Names & Sequence (5' 3') & Restriction site \\
\hline RVG F & CCCGCTAGCTCTAGAATGCCGCTGCTGCTACTGC & NheI \\
RVG R & CCCGTCGACGCGGCCGCTTACAGTCCGGTCTCACCCCCGC & SalI \\
SI F & AATTGCTCAGGAGTAGCGGGATCCTCTACCTACTGCTCC & BamHI \\
SI R & GGAGCAGTAGGTAGAGGATCCCGCTACTCCTGAGCAATT & BamHI \\
SII F & ATGCCCGAGAATCCGGGATCCGGGATGTCTTGTGACATT & Bam HI \\
SII R & AATGTCACAAGACATCCCGGATCCCGGATTCTCGGGCAT & BamHI \\
GH F & GATCCGGGTCAAGCAGACGAGGCGACTTGGGTTCCTCGCG & BamHI* \\
& GCACGAGTCGTGAAGGCACTTCCTGCT & \\
GH R & GATCCAGCAGGAAGTGCCTTCACGACTCGTGCCGCGAGGGA & BamHI* \\
& ACCCAAGTCGCCTCGTCTGCTTGACCCG & \\
\hline
\end{tabular}

* Once the pair of primers is aligned, a BamHI cohesive overhang end is formed on both sides of the ds sequence 
$6 \mathrm{mM}$ glutamine and were cultured in Erlenmeyer flasks (Corning, USA) at $37{ }^{\circ} \mathrm{C}$ with $5 \% \mathrm{CO} 2$, and agitated at $140 \mathrm{rpm}$ using a shaking incubator cabinet (CERTOMAT ${ }^{\circledR}$ CT plus, Sartorius). For the development of stable cell lines, selection of recombinant cells was achieved supplementing media with puromycin (Sigma-Aldrich).

Monoclonal antibody against rabies glycoprotein (Fontana et al. 2020) and mouse polyclonal serum against FMDV A/Arg/01 serotype were developed in our laboratory. The antigen used to obtain the polyclonal serum was a quadrivalent anti-FMDV commercially available vaccine (Bioaftogen®, Biogénesis-Bagó).

\section{Third-generation lentiviral vector packaging}

Lentiviral particles were produced by simultaneous co-transfection of HEK293 cells with four plasmids using polyethylenimine as transfecting agent. These plasmids were the packaging construct (pMDLg/pRRE), the VSV-G expressing construct (pMDG), and the Rev-expressing construct (pRSV-Rev) (Naldini et al. 1996; Dull et al. 1998), and each of the transfer vectors is obtained in the "Generation of 5D models of rabies glycoprotein trimer" section: pLVRVG(S0)-GH, pLV-RVG(SI)-GH, and pLV-RVG(SII)-GH. Forty-eight hours after transfection, the supernatants were harvested, clarified by low speed centrifugation, and frozen at $-70{ }^{\circ} \mathrm{C}$ prior to use.

\section{Stable cell line development}

sHEK cells were seeded at a concentration of $3.5 \times 10^{4}$ cells/ $\mathrm{ml}$ in 6-well plates on DMEM medium with $10 \%$ FCS. After $24 \mathrm{~h}$, supernatant was removed and the transduction was performed adding $1 \mathrm{ml}$ of lentiviral stock. At 96-h posttransduction, cells were trypsinized, resuspended on EXCELL $® 293$ medium at a cell concentration of $5 \times 10^{5}$ cells/ $\mathrm{ml}$, and cultivated on $50 \mathrm{ml}$ polypropylene tubes with filter caps (CELLSTAR CELLreactor ${ }^{\mathrm{TM}}$, Greiner Bio-One) at $140 \mathrm{rpm}$ in a shaking incubator cabinet. A multi-step gradual selection protocol with puromycin was employed based on previous works (Prieto et al. 2011). Briefly, cells were cultivated with a concentration of $1 \mu \mathrm{g} \cdot \mathrm{ml}^{-1}$ of puromycin for 5 days, and then with a concentration of $3 \mu \mathrm{g} \cdot \mathrm{ml}^{-1}$. The selection agent was gradually changed every 7 days of culture.

\section{Flow cytometry}

Approximately $2 \times 10^{5}$ cells were harvested and washed with PBS. Cells were pelleted by centrifugation at $100 \mathrm{~g}$ for $10 \mathrm{~min}$, and then resuspended in $100 \mu \mathrm{l}$ of a 1:1,000 dilution of an anti-RVG monoclonal antibody in PBS, or a 1:500 dilution of mouse anti-FMDV polyclonal antibodies in PBS. After a 30-min incubation at room temperature, cells were washed with PBS and pelleted as described previously. Cells were resuspended in a 1:500 dilution of an Alexa Fluor 488 conjugated goat anti-mouse antibody (Thermo Fisher Scientific) and incubated at room temperature in the dark for $30 \mathrm{~min}$. Finally, cells were washed, resuspended in $200 \mu \mathrm{l}$ of PBS, and analyzed in a GUAVA EasyCyte cytometer (Millipore) using Guava Express Plus Software (Millipore).

\section{Laser confocal microscopy}

Cells were immunostained as described in the "14" section, but an additional incubation was done in PBS containing Hoechst $1 \mu \mathrm{g} \cdot \mathrm{ml}^{-1}$ (ThermoFisher Scientific) and orange Cytopainter cell plasma membrane staining kit diluted 1:500 (Abcam). Finally, cells were washed, and resuspended in PBS, and $10 \mu \mathrm{l}$ of each sample was placed on microscope slides and observed in a Leica-TCS-SP8 confocal microscope (Leica). Images were analyzed using ImageJ software (Schindelin et al. 2012).

\section{VLPs analysis and characterization}

\section{VLPs concentration}

Culture media from recombinant cell lines were clarified by centrifugation at $200 \times \mathrm{g}$ and then layered over a $30 \%$ sucrose cushion. They were centrifuged at $65,000 \times \mathrm{g}$ for $3 \mathrm{~h}$ at $4{ }^{\circ} \mathrm{C}$ (Beckman JA.30 rotor, Beckman Coulter), later the sucrose cushion and culture supernatant were discarded, and the pellet was resuspended in RV-VLPs stabilization buffer (50 mM Tris - HCl, 0.15 M NaCl, 1.0 mM EDTA, pH 7.4).

\section{Sandwich ELISA}

cVLPs were quantified using a sandwich ELISA developed to quantify RV-VLPs, which has been previously described (Fontana et al. 2019).

The World Health Organization 6th International Standard for Rabies Vaccine (NIBSC, UK) was used to generate a RV-VLPs internal standard. Rabies glycoprotein content in VLP samples measured by this technique was expressed in ELISA units (EU).

\section{"Bi-specific" sandwich ELISA}

Anti-FMDV polyclonal antibodies diluted 1:1000 in carbonate buffer pH9.6 were coated in 96-well microplates (Greiner Bio-one) for $1 \mathrm{~h}$ at $37{ }^{\circ} \mathrm{C}$ and overnight at $4{ }^{\circ} \mathrm{C}$. Plates were blocked with skim milk $2 \%$ in PBS for $1 \mathrm{~h}$ at $37{ }^{\circ} \mathrm{C}$. Then, two-fold serial dilutions of cVLP samples in PBS, Tween-20 $0.05 \%$ skim milk $0.2 \%$ were incubated for $1 \mathrm{~h}$ at $37{ }^{\circ} \mathrm{C}$. After that, an anti-rabies rabbit polyclonal 
biotin-conjugated antibody was incubated (diluted 1:2000 in PBS, Tween-20 0.05\% skim milk $0.2 \%$ ) followed by an incubation with streptavidin-HRP (horseradish peroxidase) complex (Sigma-Aldrich) diluted 1:10,000 in PBS, Tween$200.05 \%$ skim milk $0.2 \%$. Finally, $100 \mu \mathrm{l}$ of a chromogenic substrate solution $\left(0.5 \mathrm{mg} \cdot \mathrm{ml}^{-1}\right.$ o-phenylenediamine dihydrochloride (Sigma-Aldrich), $0.5 \mu \mathrm{l} . \mathrm{ml}^{-1} \mathrm{H}_{2} \mathrm{O}_{2} 30$ vol. (8\%), $50 \mathrm{mM}$ citrate/phosphate buffer, $\mathrm{pH}$ 5.3) was added per well and incubated for $15 \mathrm{~min}$ to reveal the reaction. It was stopped by adding $50 \mu \mathrm{l}$ of a $1 \mathrm{M} \mathrm{H}_{2} \mathrm{SO}_{4}$ solution and the optical density was measured at $492 \mathrm{~nm}$ in a plate reader spectrophotometer (Labsystems Multiskan $\left.{ }^{\circledR}\right)$. Plates were washed six times with PBS Tween-20 0.05\% for each 1-h incubation.

\section{Immunogold labeling transmission electron microscopy (TEM)}

Ten microliters of concentrated cVLP samples were adsorbed on 200 mesh Formvar/carbon-coated grids for $2 \mathrm{~min}$, and then washed 3 times with distilled water. The excess was removed with blotting paper and then the grid was blocked with PBS-BSA $1 \%$ for $30 \mathrm{~min}$ at room temperature. Later, the grids were washed as previously described and incubated with a 1:20 dilution of anti-FMDV antibodies (mouse) in PBS-BSA 0.05\% at room temperature in a humid chamber for $1 \mathrm{~h}$. After a washing step, the grid was incubated with a secondary $20 \mathrm{~nm}$ gold-conjugated antibody (Colloidal Gold-AffiniPure goat anti-mouse IgG, Jackson ImmunoResearch) diluted 1:20 in PBS-BSA $0,05 \%$ for $1 \mathrm{~h}$ at room temperature in a humid chamber. Finally, grids were washed and negatively stained with uranyl acetate $2 \%$ for $1 \mathrm{~min}$, and then washed with distilled water and dried at room temperature for $5 \mathrm{~min}$. Samples were examined using a transmission electron microscope (JEM-2100 plus, JEOL) at $100 \mathrm{kV}$. Images were visualized and processed using Image J software (Schindelin et al. 2012).

\section{Results}

\section{Identification of insertion sites in rabies glycoprotein}

The main goal of this work was to assess the ability of RVVLPs to expose heterologous epitopes, by generation of RVG fusion proteins. The first objective was to find suitable regions to insert the heterologous epitope so that it is exposed on the surface of RVG ectodomain, and does not alter its correct folding. Certain criterions were taken into account to identify adequate sites: they must not have secondary structure, be exposed to the solvent, not be involved in protomer-protomer interactions, and denote a low sequence identity between another Lyssavirus. On the other hand, our goal was not to alter RVG antigenic sites in order to maintain as much as possible the protection elicited against rabies virus.

A multiple alignment of RVG and 16 other Lyssavirus glycoproteins was analyzed, focusing on AA 1-375 of the ectodomain of the mature proteins (Fig. 1). Four regions with low sequence identity were found: AA 160-168 (site I), AA 181-188 (site II), AA 243-251 (site III), and AA 352-357 (site IV).

To visualize the structure of non-conserved regions in rabies glycoprotein, the ectodomain was modeled using as template the crystalized structure of Mokola virus glycoprotein (MOKV G) ectodomain protomer, in its postfusion state (Protein Data Bank access code: 6TMR, 65\% AA sequence identity with RVG) (Belot et al. 2020). As the obtained structure depicts a post-fusion conformation and does not represent the native state of RVG, a comparative modeling was carried out using a pre-fusion structure of vesicular stomatitis virus glycoprotein (VSV-G) ectodomain trimer (Protein Data Bank access code: 5I2S) (Roche et al. 2007). Fusion domain (FD, AA 55-180), trimerization domain (TrD, AA 1-17, 272-373), and pleckstrin homology domain (PHD, AA 35-46, 191-259) of RVG post-fusion obtained model were superimposed over the respective domains of VSV-G trimer and the regions connecting them were refined. RVG pre-fusion protomer model, which comprises residues 1-374 of RVG (Fig. 2A), was analyzed using QMEAN throwing a value of -4.20 , which is acceptable for a protein of its size. On the other hand, the model has an acceptable stereochemistry quality, having $85 \%$ of the residues on the most favored regions of the Ramachandran plot (Fig. 2B).

The final RVG trimer model (Fig. 3) was used to identify the non-conserved regions previously found. They present a loop structure and are exposed in the surface on the protein. Moreover, they are not located in the protomer-protomer interface or rabies reported antigenic sites. Sites I and II protrude from the surface of the protein, and are located on the lateral of the trimer above the fusion domain. On the other hand, site III is located on top of the protein between rabies a.s 1 and a.s 2, its conformation being held by a proximal disulfide bridge between cysteines 223 and 252. In the same manner, site IV is stabilized by a proximal disulfide bridge between residues 344 and 351, and it is localized on the trimerization domain on the lateral of the trimer.

In order to confirm the capacity of these regions to expose the heterologous epitope, we selected sites I and II to continue working, as they are not located near disulfide bridges (known to be important for the tertiary structure) and are more distant from RVG antigenic sites. On the 


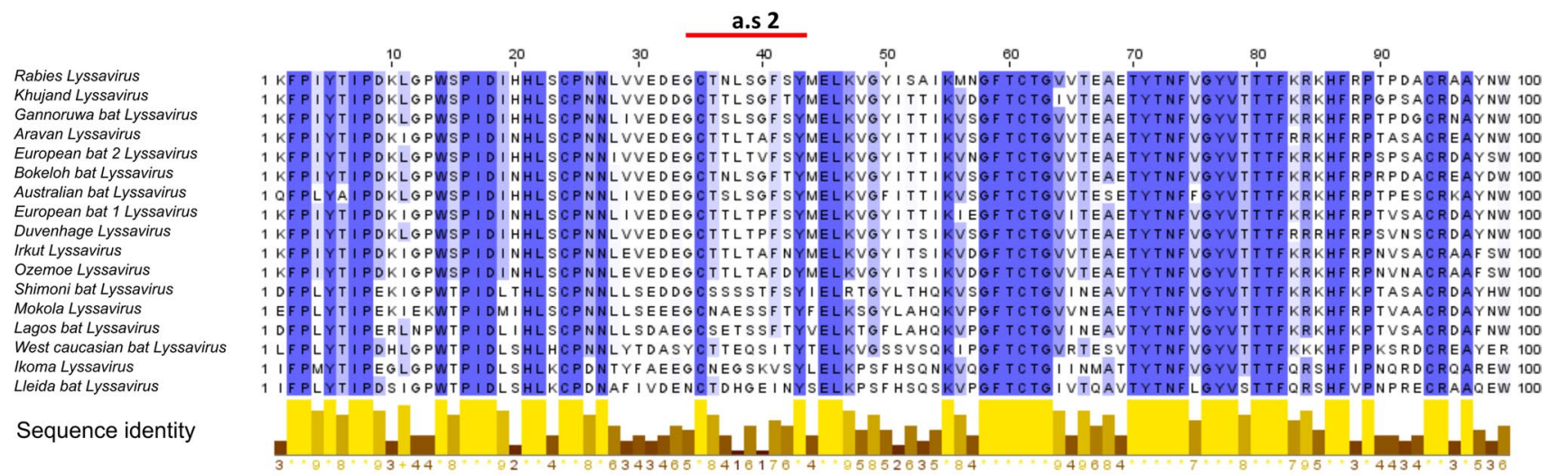

Rabies Lyssavirus Gannoruwa bat Lyssavirus Aravan Lyssavirus European bat 2 Lyssavirus Bokeloh bat Lyssavirus Australian bat Lyssavirus European bat 1 Lyssavirus Duvenhage Lyssavirus Irkut Lyssavirus Ozemoe Lyssavirus Shimoni bat Lyssavirus Mokola Lyssavirus Lagos bat Lyssavirus West caucasian bat Lyssavirus Lleida bat Lyssavirus

Sequence identity
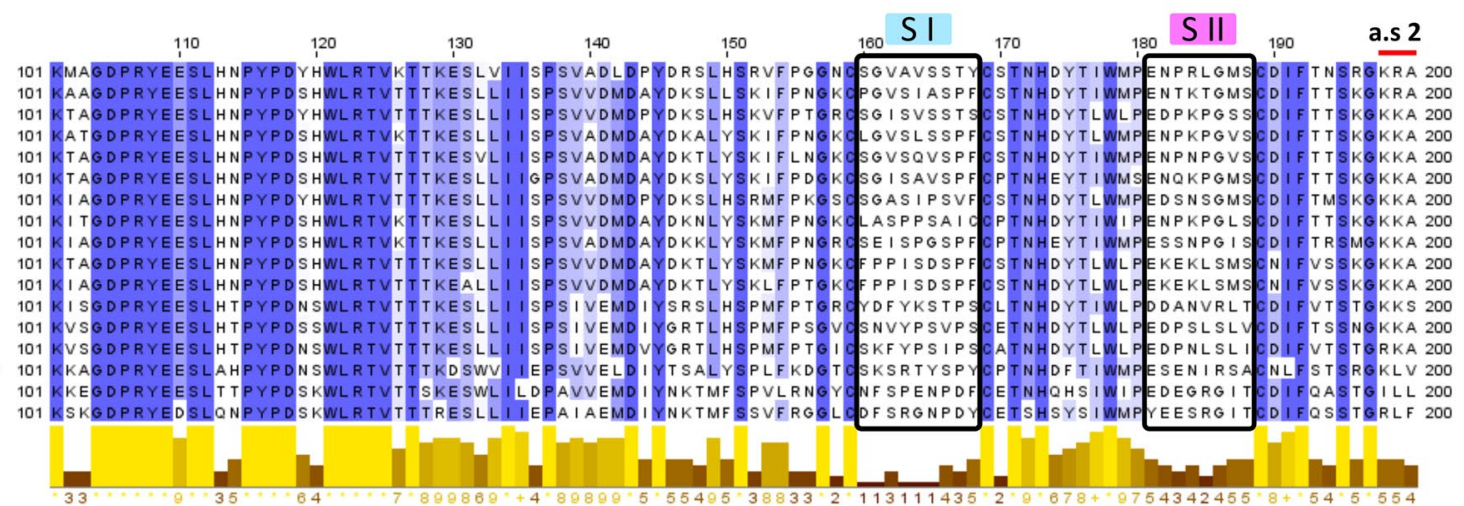

Rabies Lyssavirus
Khujand Lyssavirus
Gannoruwa bat Lyssavirus
Aravan Lyssavirus
European bat 2 Lyssavirus
Bokeloh bat Lyssavirus
Australian bat Lyssavirus
European bat 1 Lyssavirus
Duvenhage Lyssavirus
Irkut Lyssavirus
Ozemoe Lyssavirus
Shimoni bat Lyssavirus
Mokola Lyssavirus
Lagos bat Lyssavirus
West caucasian bat Lyssavirus
lkoma Lyssavirus
Lleida bat Lyssavirus

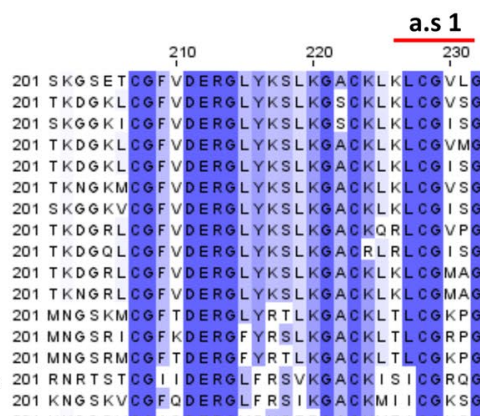

Lleida bat Lyssavirus

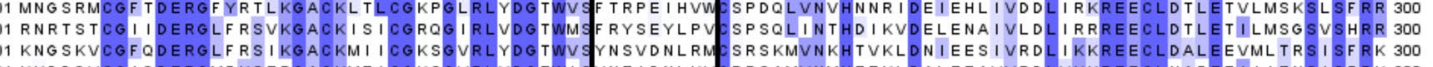

Sequence identity

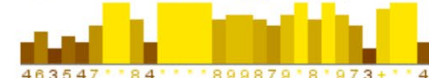

Rabies Lyssavirus
Khujand Lyssavirus
Gannoruwa bat Lyssavirus
Aravan Lyssavirus
European bat 2 Lyssavirus
Bokeloh bat Lyssavirus
Australian bat Lyssavirus
European bat 1 Lyssavirus
Duvenhage Lyssavirus
Irkut Lyssavirus
Ozemoe Lyssavirus
Shimoni bat Lyssavirus
Mokola Lyssavirus
Lagos bat Lyssavirus
West caucasian bat Lyssavirus
Ikoma Lyssavirus
Lleida bat Lyssavirus

Sequence identity

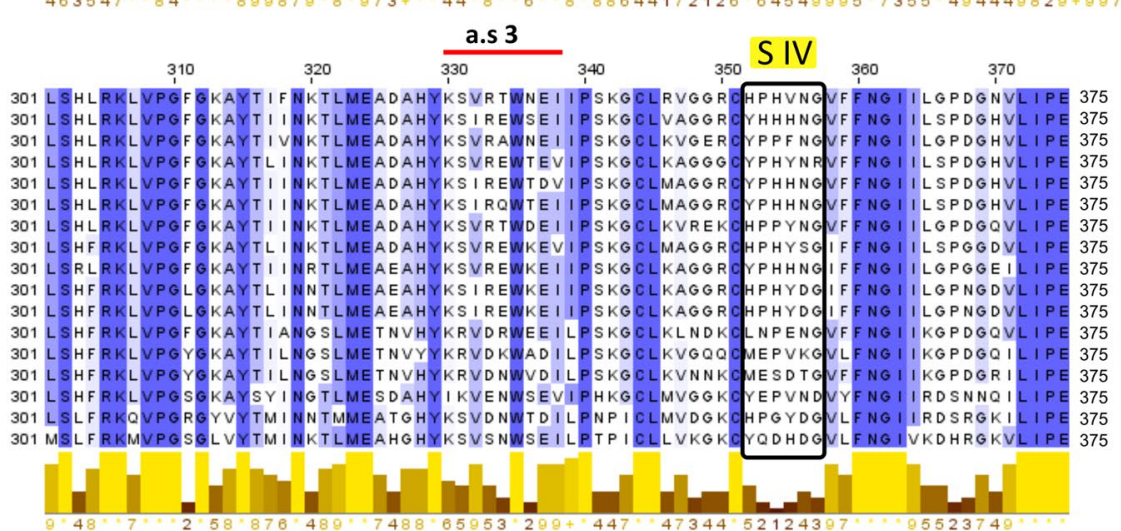

other hand, we also selected the $\mathrm{N}$-terminal region to assess the insertion of the heterologous epitope, as an alternative strategy that could diminish the chances of misfolding of the carrier protein. Thus, three fusion proteins displaying the heterologous sequence in different regions were designed (Fig. 4). 
४Fig. 1 Multiple alignment of Lyssavirus glycoproteins. To identify non-conserved regions in Lyssavirus glycoproteins, a multiple alignment of 17 sequences including rabies Lyssavirus was carried out. The alignment encompasses AA 1 to 375 of mature glycoproteins. Regions with high sequence identity are highlighted in blue. Four regions with low sequence identity were identified as possible insertion sites, called I to IV (S I, S II, S III, and S IV), and are marked in the alignment within black rectangles. Besides the low identity sequence, these regions do not comprise any important RVG antigenic site (A.S 1, 2, and 3), which have been marked with red lines on the alignment

\section{Expression and antigenic characterization of fusion glycoproteins}

The coding sequence of the designed fusion glycoproteins, named RVG(S0)-GH, RVG(SI)-GH, and RVG(SII)$\mathrm{GH}$, was introduced in sHEK293 cells by lentiviral transgenesis. Stable expressing cell lines were generated by selective pressure with antibiotics and the expression of fusion proteins was first assessed by flow cytometry. The three fusion proteins were detected in the plasmatic membrane by an anti-RVG mAb (Fig. 5). Moreover, the heterologous epitope was detected by anti-FMDV antibodies raised against FMDV inactivated virus in every fusion protein (Fig. 5). To confirm the subcellular localization of the fusion proteins, marked cells were observed by immunofluorescence microscopy. Fusion glycoproteins were detected on the plasmatic membrane with both a mAb anti-RVG (Fig. 6A) and anti-FMDV antibodies (Fig. 6B). RVG HEK293 expressing cells (Fontana et al. 2014) immunostained with anti-FMDV antibodies were included as a negative control, as well as HEK293 wild type cells immunostained with both anti-RVG and antiFMDV antibodies.

These results allow us to conclude that the heterologous epitope is exposed on the surface of each of the insertion sites analyzed, as it is able to interact with specific antibodies, adopting a conformation similar to that found on the virus capsid.

\section{cVLPs budding and epitope display assessment}

In previous work, our group has demonstrated that with the only expression of the RVG in suspension HEK293 cells, highly immunogenic RV-VLPs are budded to the cell culture supernatant (Fontana et al. 2014; Fontana et al. 2015). Here, to assess whether these novel RVG fusion proteins, carrying a heterologous epitope, are able to bud from the plasmatic membrane forming cVLPs, culture media of recombinant cell lines were analyzed by a rabies-specific sandwich ELISA. As can be seen in Fig. 7, cVLPs were detected in the culture medium of each of the recombinant cell lines, proving that the insertion of the heterologous epitope does not impede VLPs budding from plasma membrane.

Later, to assess if the cVLPs are able to expose the heterologous epitope in their surface, a concentration step was carried out by sucrose cushion centrifugation of culture media of producer cells. Concentrated cVLP samples were analyzed by a "bi-specific" ELISA, using anti-FMDV antibodies to capture the antigen and anti-RVG antibodies to detect the particles. As a control, RVG VLPs were included in the experiment (Fontana et al. 2015). Anti-FMDV antibodies attached to the plate were able to interact with the heterologous epitope present in the three cVLPs designed, proving that it is correctly exposed and with an adequate antigenic conformation on the surface of the particles (Fig. 8). To characterize more the particles, we performed an immunoelectron microscopy of cVLPs concentrated samples using FMDV antibodies. We were able to detect the fusion protein on the surface of cVLPs (Fig. 9), confirming that the heterologous epitope is correctly displayed. Moreover, cVLPs were measured (Fig. 9) and the sizes are similar to those reported for RV-VLPs, approximately 50-60 nm (Fontana et al. 2014): $62 \pm 15 \mathrm{~nm}$ for RVG(S0)-GH VLPs, $58 \pm 16 \mathrm{~nm}$ for RVG(SI)-GH VLPs, and $60 \pm 20 \mathrm{~nm}$ for RVG(SII)-GH VLPs.

Thus, we were able to predict adequate regions in RVG to insert the heterologous epitope and confirmed its correct antigenic conformation and surface availability both in producing cells and in cVLP samples.

\section{Discussion}

cVLPs have become an interesting platform for heterologous antigen display, as they allow the repetitive incorporation of sequences or domains in a particulated context, which boost the immune response triggered against them (Jeong and Seong 2017). Moreover, they facilitate the incorporation of antigens in well-established biosecure expression platforms that can avoid difficulties such as the requirement of high biosecurity levels in case of highly infectious virus like FMDV.

However, the incorporation of a foreign AA sequence without altering the correct folding of the carrier protein as well as not impeding VLPs formation while retaining the surface display and correct antigenic conformation of the heterologous sequence entails some difficulties.

In contrast to non-enveloped VLPs, which have been extensively studied to display foreign antigens, little information is found on that subject regarding enveloped VLPs. They have the advantage of being continuously produced by natural budding from the plasmatic membrane or through 

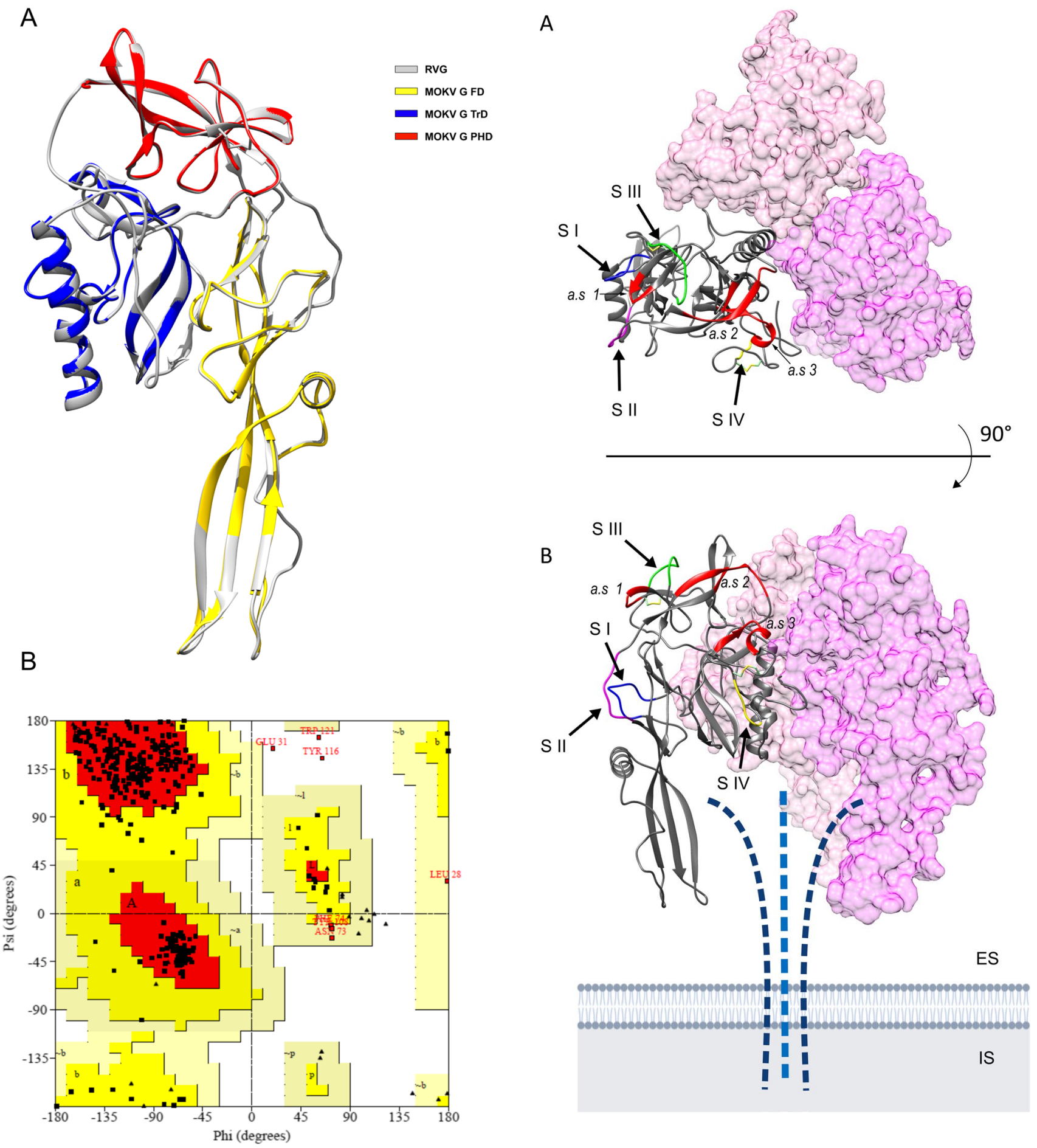

Fig. 2 RVG model construction. A Overlap 3D image of MOKV G domains and pre-fusion RVG protomer model. FD (AA 55-180), TrD (AA 1-17, 272-373), and PHD (AA 35-46, 191-259) domains of MOKV $\mathrm{G}$ used as a template for homology modeling were overlapped on RVG pre-fusion protomer model obtained. B. Ramachandran plot of RVG model. Of residues, $84.9 \%$ are located on the most favored regions of the map (red), $12.8 \%$ are located on additional allowed regions (bright yellow), $1.3 \%$ on generously allowed regions (dim yellow), and $1 \%$ on disallowed regions (white)

Fig. 3 Identification of insertion sites in the rabies glycoprotein ectodomain trimer model. A homology modeling was carried out to obtain the structure of RVG in post-fusion state using MOKV G as a template. Specific domains of RVG monomer model were superimposed in the VSV-G pre-fusion state trimer to obtain the structure of RVG trimer in the native state. A monomer is depicted in ribbons (dark gray) to assess the secondary structures, while the other monomers are shown by their molecular surfaces (magenta and pink). Insertion sites I to IV (S I, S II, S III, S IV) were marked with arrows, while most important RVG antigenic sites were colored in red (a.s 1, a.s 2, and a.s 3). A Up-view of RVG trimer ectodomains. B Lateral view of RVG trimer indicating the relative position of the plasmatic membrane. ES extracellular space. IS intracellular space. Dotted lines represent the C-terminal region of each of the monomers, including the transmembrane and cytoplasmatic domains 
Fig. 4 Design of fusion RVG displaying the FMDV $G-H$ loop. Three chimeric RVG proteins were designed, displaying the heterologous sequence in different regions. RVG(S0)-GH carries the sequence in its $\mathrm{N}$-terminal region, right after the signal peptide sequence (s.p). RVG(SI)-GH and RVG(SII)GH carry the heterologous sequence on the insertion sites I and II (S I and SII), between AA $164-165$ and $184-185$ of mature proteins, respectively. t.d transmembrane domain. c.d cytoplasmatic domain. GH: AA 140-160 of VP1 (A/Arg/2001): GSSRRGDLGSLAARV-

\section{VKALPA}
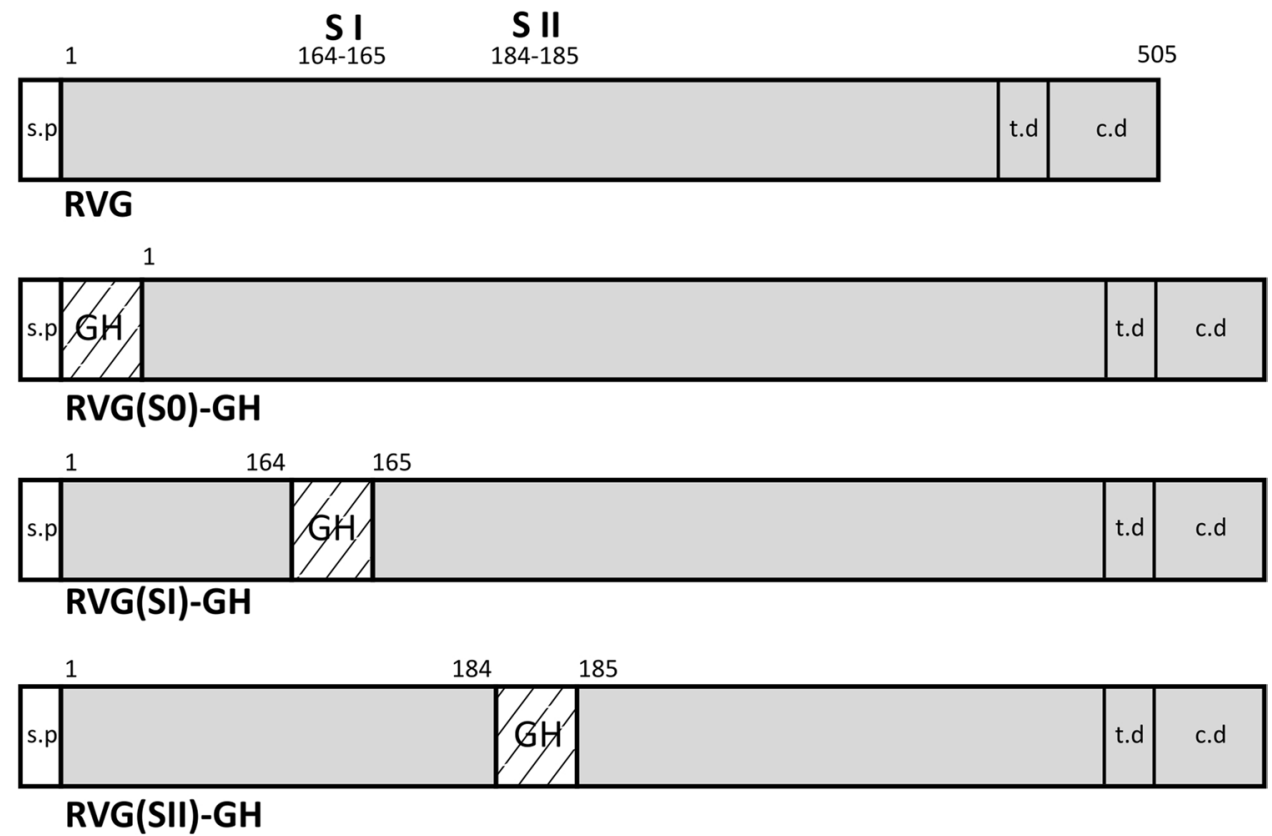
$\begin{array}{lllll}\text { RVG(S0)-GH } & \text { RVG(SI)-GH } & \text { RVG(SII)-GH } & \text { RVG }\end{array}$
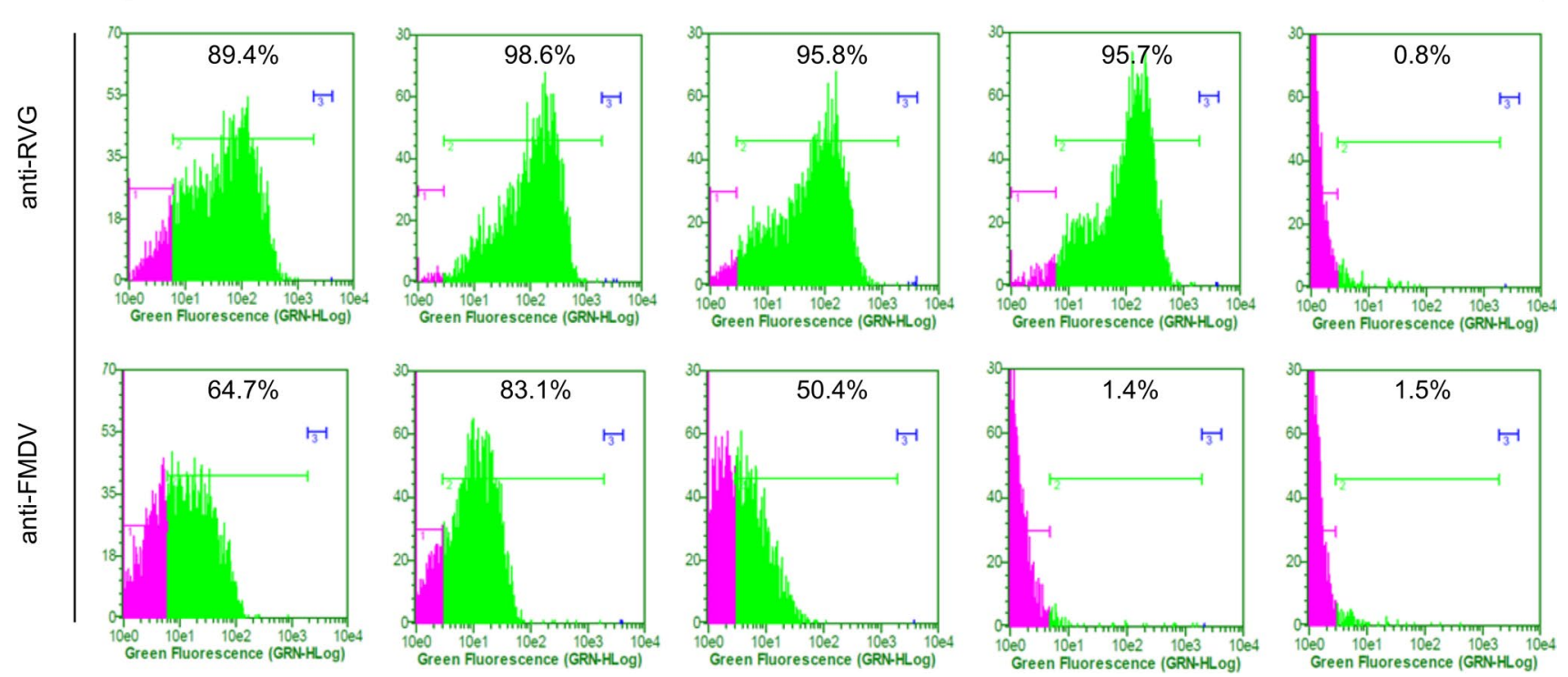

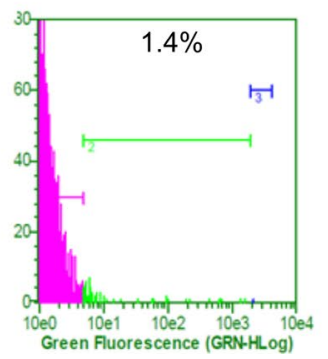

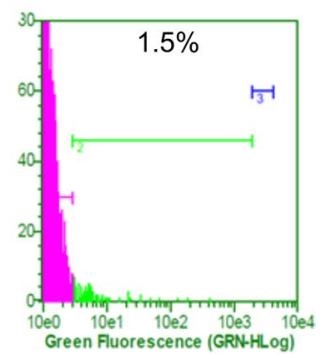

Fig. 5 Fusion protein expression analysis by flow cytometry. Recombinant sHEK293 cells expressing the fusion proteins RVG(S0)-GH, RVG(SI)-GH, and RVG(SII)-GH were marked with an anti-RVG $\mathrm{mAb}$ or with anti-FMDV polyclonal antibodies, and later with an AlexaFluor488 conjugated secondary antibody. A RVG expressing

multivesicular bodies recruited by the endosomal sorting complexes required for transport pathway (Votteler and Sundquist 2013; Pijlman 2015), and therefore do not require a cell disruption step that entails further purification steps to remove cellular contaminants (Vicente et al. 2011; Donaldson et al. 2015). clone (Fontana et al. 2015) and wild type sHEK293 were included as negative controls against the heterologous epitope and RVG, respectively. Cells were analyzed with a GUAVA EasyCyte cytometer and the data was acquired with GUAVA ExpressPlus software. Marker 1, negative population. Markers $2-3$, positive population

The main objective of this work was to assess RVG capacity of displaying foreign antigens in the context of enveloped VLPs, by identifying adequate regions in its ectodomain, to establish a heterologous antigen presentation platform for vaccine applications. In order to do so, we considered both evolutive and structural 
A
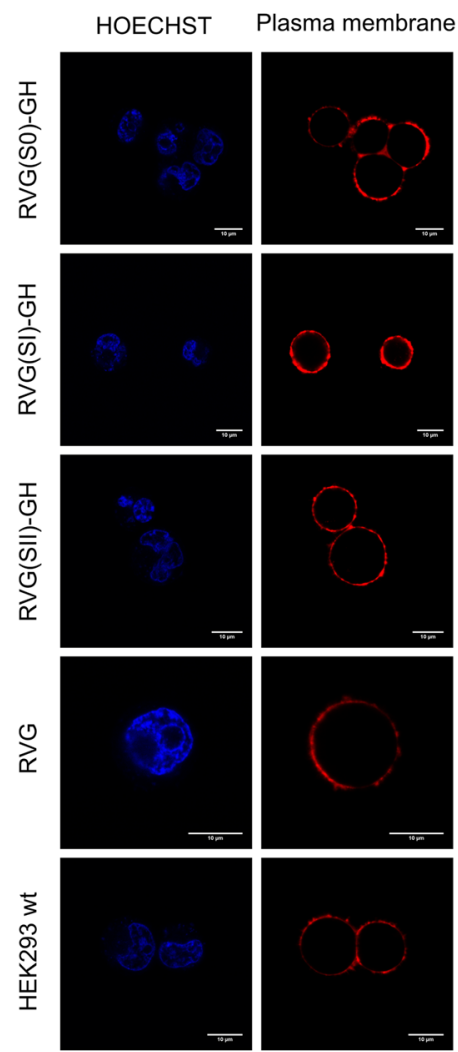
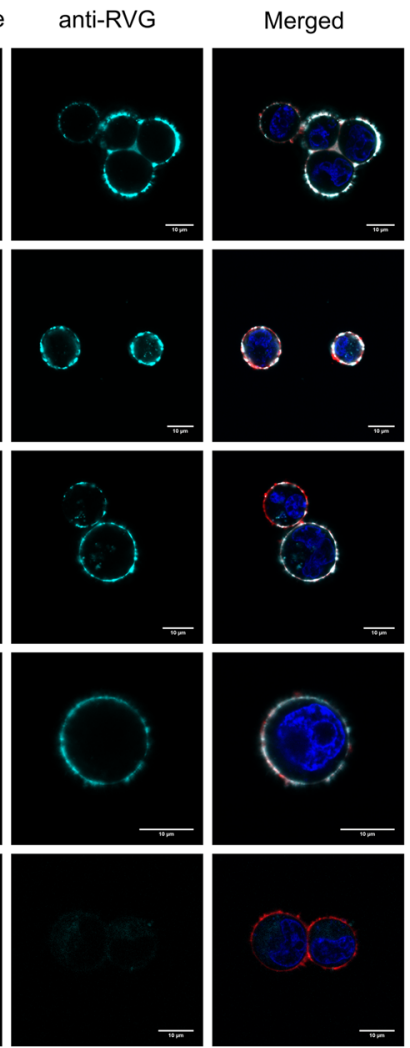
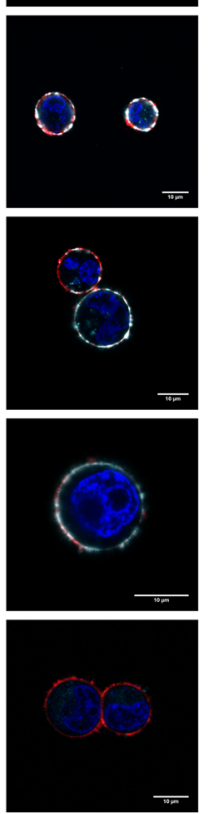

Fig. 6 Subcellular localization analysis of fusion glycoproteins by confocal laser microscopy. Recombinant sHEK293 cells expressing the fusion proteins were marked with an anti-RVG $\mathrm{mAb}$ or with antiFMDV polyclonal antibodies, and later with an AlexaFluor488 conjugated secondary antibody prior to observation. For an easier differentiation between each antibody staining, the color of AlexaFluor488

criterions to ensure a minimal risk of protein misfolding or inadequate display of the foreign sequence. We compared the sequences of Lyssavirus glycoproteins in order to identify non-conserved regions (Fig. 1), which in case of homologous proteins can indicate structural flexibility and could be modified reducing the chances of altering the tertiary structure of the protein. In fact, this strategy has been carried out previously to produce insertions in other viral proteins (Gedvilaite et al. 2000; Bonaldo et al. 2006).

The structure of the non-conserved regions were analyzed on the RVG model trimer obtained (Fig. 3), identifying loop structures in each of the insertion sites. S I and S II are proximately located in the lateral of the model opposing the trimerization domain, while S III protrudes from the top of the protein closely to a.s 1 and a.s 2 . On the other hand, S IV is located on the lateral of the monomer, near the interface monomer-monomer. As previously mentioned, S III and S IV seem to be stabilized by proximal disulfide bridges that are absolutely conserved
B

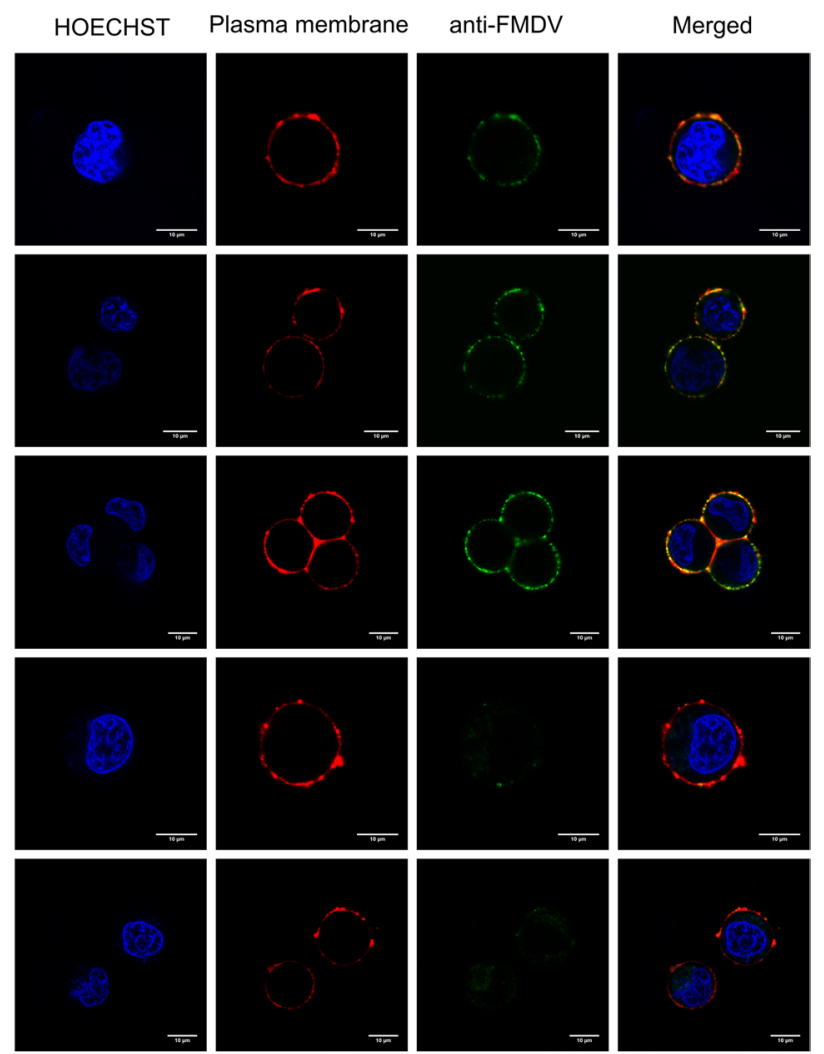

channel on anti-RVG marked cells was changed to cyan. Nuclei were stained with Hoechst and plasma membrane with CytoPainter orange (Abcam). A Fusion protein expressing cells marked with mAb antiRVG. B Fusion protein expressing cells marked with anti-FMDV antibodies. Scale bar size: $10 \mu \mathrm{m}$

in all Lyssavirus glycoproteins, which could indicate a relevant role in the adequate folding and function. To avoid disrupting these interactions that seem to be biologically relevant, and not to impair the availability of a.s 1 and a.s 2 to BCRs, insertions sites I and II were selected to continue the work. Nevertheless, there is evidence that S III acts as a "hinge" region in Lyssavirus glycoproteins, allowing the separation of the protein in two independent domains that can be interchanged between different Lyssavirus glycoproteins (Desmézières et al. 1999; Jallet et al. 1999). However, this structural flexibility remains to be studied in the context of VLPs. Furthermore, the $\mathrm{N}$-terminal extreme of the protein was also selected as an insertion site ( $\mathrm{S} 0$ ) because it could be modified reducing the chances of misfolding of RVG, although in the 3D trimer model it does not appear as a region with a high surface exposure.

The coding sequence of the mayor FMDV antigenic site and main target of NAs was inserted in the chosen regions, and third-generation lentiviral vectors carrying the fusion 


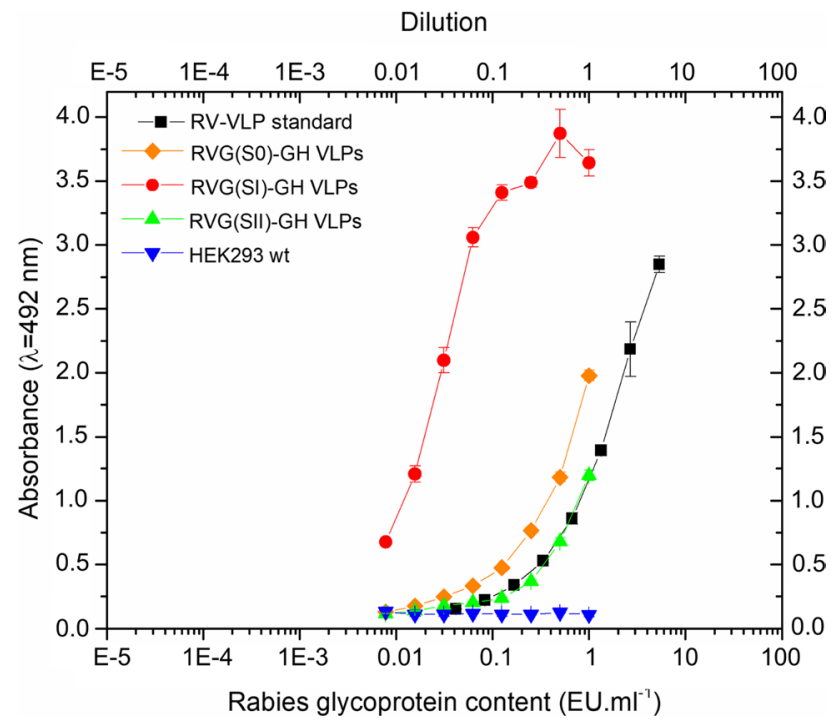

Fig. 7 cVLP detection in culture media. A RVG-specific sandwich ELISA was carried out to detect and quantify cVLP in recombinant cell lines culture media. Anti-RVG antibodies were used to capture the cVLPs, while biotin-conjugated anti-RVG antibodies were used to detect the particles. A streptavidin-HRP conjugate was incubated, and the reaction was revealed adding a chromogen forming substrate. A RVG VLPs standard that had been previously valuated against the World Health Organization 6th International Standard for Rabies Vaccine (NIBSC) was included. Samples were analyzed in duplicate. Mean and standard deviation are shown

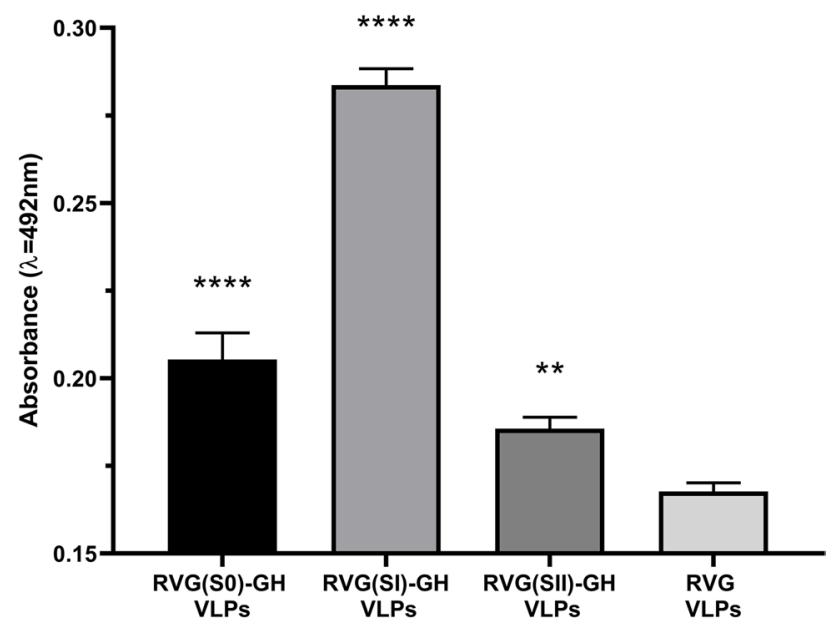

Fig. 8 G-H loop display assessment in cVLPs. Concentrated cVLP samples were captured by anti-FMDV antibodies and detected by biotin-conjugated anti-RVG antibodies. A streptavidin-HRP complex was incubated and later a chromogen substrate was added to reveal the reaction. As a negative control, concentrated RVG VLPs were included in the experiment. D'Agostino and Pearson normality test passed $(\alpha=0.05)$. Dunnett's multiple comparisons test vs control: $* * * * p$ value $<0.0001 ; * * p$ value $=0.0054$. Samples were analyzed in triplicate. Mean and standard deviation are shown protein coding sequences were generated (Fig. 4). Stable expressing sHEK293 cell lines were generated by lentiviral transgenesis, and the correct protein subcellular localization was confirmed by flow cytometry (Fig. 5) and laser confocal microscopy (Fig. 6). The insertion of the heterologous sequence did not impede the normal intracellular traffic and plasmatic membrane localization of the fusion glycoproteins, as was revealed by labeling the cells with a mAb anti-RVG. Moreover, high levels of expression of each of the fusion proteins were obtained. Furthermore, we confirmed the adequate exposition and antigenic conformation of the heterologous epitope in the surface of the chimeric proteins, as it was recognized by specific FMDV antibodies.

Later, we confirmed the ability of fusion proteins to bud from the plasmatic membrane to form enveloped cVLPs, detecting them in the culture medium with an anti-RVG sandwich ELISA (Fig. 7).

Finally, we confirmed the ability of the cVLPs to display the heterologous sequence in their surface, as they were detected by specific anti-FMDV and anti-RVG antibodies in a "bi-specific" ELISA of concentrated samples (Fig. 8). Interestingly, the heterologous region was detected both on the N-terminal region of the carrier protein, where the peptide has a higher degree of liberty to acquire different conformations, as well as in middle regions where it is more limited. These results agree with the fact that $G-H$ loop sequence of FMDV is intrinsically disordered and therefore able to adopt several conformations in all of the serotypes studied (Azuma and Yoneda 2009). Preliminary results show that there are differences in the degree of antiGH loop antibodies recognition by each of the fusion proteins, where RVG(SII)-GH VLPs are able to induce higher specific signals per VLPs unit (results not shown). These differences could be attributed to different conformations of the heterologous epitope on the insertion site, which produce changes in the recognition by specific antibodies. Future experiments will focus on assessing and comparing the immune response triggered by these cVLPs against the heterologous epitope.

In conclusion, through the identification of suitable insertion sites following a structural and evolutive approach, we rationally designed cVLPs based on RVG which expose a major antigenic site of FMDV in three different regions.

This is the first work that searches adequate regions for heterologous antigen display in RVG in the context of VLPs for vaccine applications. This technology allows to continuously express the antigen in an easily scalable suspension culture system using serum-free medium, and does not require a cell disruption step becoming an interesting platform for new generation vaccine development. 


\section{RVG(S0)-GH VLPS}
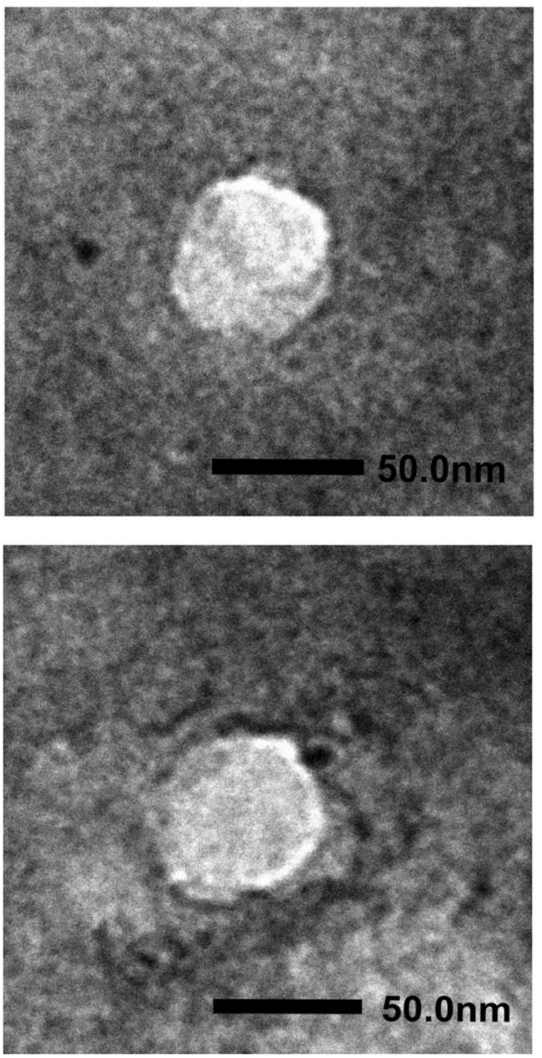

RVG(SI)-GH VLPS
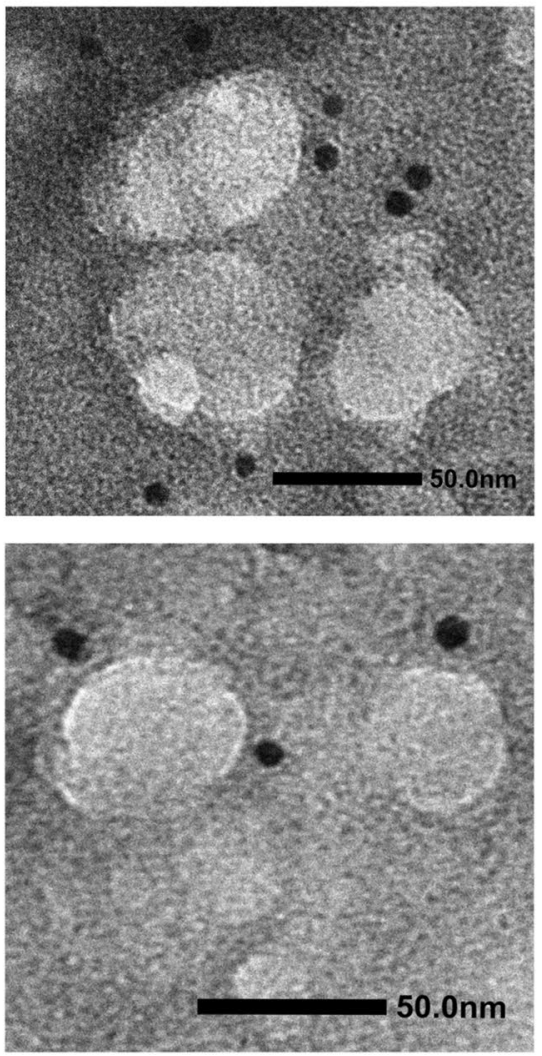

RVG(SII)-GH VLPS
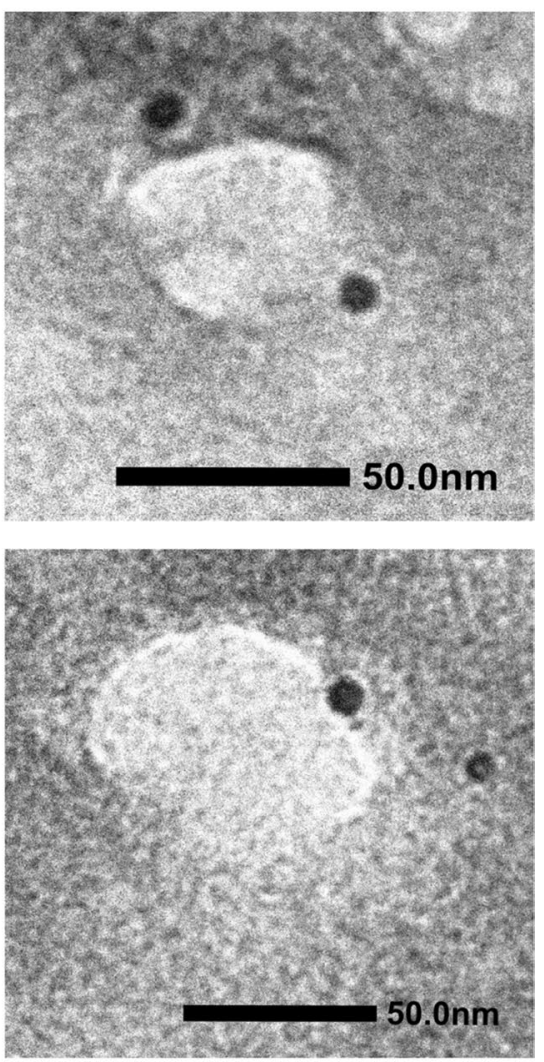

Fig. 9 TEM of anti-FMDV marked cVLPs. Concentrated cVLP samples were adsorbed on Formvar/carbon-coated copper grids and then incubated with anti-FMDV antibodies and a secondary antibody

Acknowledgements The authors would like to thank Dr. Alberto S. Garay (Physics Department, School of Biochemistry and Biological Sciences, Universidad Nacional del Litoral, Santa Fe, Argentina) for his help in the development of the 3D model of rabies glycoprotein trimer.

Author contribution EG, DF, and CP conceived and designed research. EG and LL conducted experiments. EG wrote the manuscript. DF, CP, and RK revised the manuscript. All authors read and approved the final manuscript.

Funding This work was supported by the Agencia Nacional de Promoción Científica y Tecnológica, Argentina (FONCyT-PICT-2017-1087).

Data availability Not applicable

Code availability Not applicable

\section{Declarations}

Ethics approval Not applicable

Consent to participate Not applicable

Consent for publication Not applicable conjugated to colloidal gold $(20 \mathrm{~nm})$. Uranyl acetate $2 \%$ was used as a contrast agent for negative staining. cVLPs size was measured $(N=40$ for each cVLP $)$

Conflict of interest The authors declare no competing interests.

\section{References}

Aston-Deaville S, Carlsson E, Saleem M, Thistlethwaite A, Chan H, Maharjan S, Facchetti A, Feavers IM, Alistair Siebert C, Collins RF, Roseman A, Derrick JP (2020) An assessment of the use of hepatitis B virus core protein virus-like particles to display heterologous antigens from Neisseria meningitidis. Vaccine 38:32013209. https://doi.org/10.1016/j.vaccine.2020.03.001

Azuma H, Yoneda S (2009) Structure and dynamics of the GH loop of the foot-and-mouth disease virus capsid. J Mol Graph Model 28:278-286. https://doi.org/10.1016/j.jmgm.2009.08.006

Beaumont E, Patient R, Hourioux C, Dimier-Poisson I, Roingeard P (2013) Chimeric hepatitis B virus/hepatitis C virus envelope proteins elicit broadly neutralizing antibodies and constitute a potential bivalent prophylactic vaccine. Hepatology 57:13031313. https://doi.org/10.1002/hep.26132

Belot L, Ouldali M, Roche S, Legrand P, Gaudin Y, Albertini AA (2020) Crystal structure of Mokola virus glycoprotein in its post-fusion conformation. PLoS Pathog 16:e1008383. https:// doi.org/10.1371/journal.ppat.1008383

Benkert P, Biasini M, Schwede T (2011) Toward the estimation of the absolute quality of individual protein structure models. 
Bioinformatics 27:343-350. https://doi.org/10.1093/bioinforma tics/btq662

Benmansour A, Leblois H, Coulon P, Tuffereau C, Gaudin Y, Flamand A, Lafay F (1991) Antigenicity of rabies virus glycoprotein. J Virol 65:4198-4203. https://doi.org/10.1007/ 978-3-642-70060-6_1

Bonaldo MC, Garratt RC, Freire MS, Galler R (2006) Expression of foreign protein epitopes at the surface of recombinant yellow fever 17D viruses based on three-dimensional modeling of its envelope protein. Cell Biochem Biophys 44:313-324. https://doi.org/10. 1385/CBB:44:3:313

Burman A, Clark S, Abrescia NGA, Fry EE, Stuart DI, Jackson T (2006) Specificity of the VP1 GH Loop of foot-and-mouth disease virus for $\alpha \mathrm{v}$ integrins. J Virol 80:9798-9810. https://doi.org/10. 1128/JVI.00577-06

Buthelezi SG, Dirr HW, Chakauya E, Chikwamba R, Martens L, Tsekoa TL, Stoychev SH, Vandermarliere E (2016) The Lyssavirus glycoprotein: a key to cross-immunity. Virology 498:250-256. https://doi.org/10.1016/j.virol.2016.08.034

Chackerian B (2007) Virus-like particles: flexible platforms for vaccine development. Expert Rev Vaccines 6:381-390. https://doi.org/10. 1586/14760584.6.3.381

Charlton Hume HK, Vidigal J, Carrondo MJT, Middelberg APJ, Roldão A, Lua LHL (2019) Synthetic biology for bioengineering viruslike particle vaccines. Biotechnol Bioeng 116:919-935. https:// doi.org/10.1002/bit.26890

Clarke BE, Newton SE, Carroll AR, Francis MJ, Appleyard G, Syred AD, Highfield PE, Rowlands DJ, Brown F (1987) Improved immunogenicity of a peptide epitope after fusion to hepatitis B core protein. Nature 330:381-384. https://doi.org/10.1038/33038 $1 \mathrm{a} 0$

Czarnota A, Anna O, Pihl AF, Prentoe J (2020) Specific antibodies induced by immunization with hepatitis $\mathrm{B}$ virus-like particles carrying hepatitis $\mathrm{C}$ virus envelope glycoprotein 2 epitopes show differential neutralization efficiency. Vaccine 8:1-19. https://doi. org/10.3390/vaccines 8020294

del Carmen Morán-García A, Rivera-Toledo E, Echeverría O, VázquezNin G, Gómez B, Bustos-Jaimes I (2016) Peptide presentation on primate erythroparvovirus 1 virus-like particles: in vitro assembly, stability and immunological properties. Virus Res 224:12-18. https://doi.org/10.1016/j.virusres.2016.08.007

Delpeyroux F, Chenciner N, Lim A, Malpièce Y, Blondel B, Crainic R, Van Der Werf S, Streeck RE (1986) A poliovirus neutralizaton epitope expressed on hybrid hepatitis B surface antigen particles. Science 80(233):472-475. https://doi.org/10.1126/science.24254 33

Desmézières E, Jacob Y, Saron MF, Delpeyroux F, Tordo N, Perrin P (1999) Lyssavirus glycoproteins expressing immunologically potent foreign $\mathrm{B}$ cell and cytotoxic $\mathrm{T}$ lymphocyte epitopes as prototypes for multivalent vaccines. J Gen Virol 80:2343-2351. https://doi.org/10.1099/ 0022-1317-80-9-2343

Donaldson B, Al-Barwani F, Young V, Scullion S, Ward V, Young S (2015) Virus-like particles, a versatile subunit vaccine platform. Adv Deliv Sci Technol 2014:159-180. https://doi.org/10.1007/ 978-1-4939-1417-3_9

Dull T, Zufferey R, Kelly M, Mandel RJ, Nguyen M, Trono D, Naldini L (1998) A third-generation lentivirus vector with a conditional packaging system. J Virol 72:8463-8471. https://doi.org/10.1128/ JVI.72.11.8463-8471.1998

Eswar N, Webb B, Marti-renom MA, Madhusudhan MS, Eramian D, Shen M, Pieper U, Sali A (2006) Comparative protein structure modeling using modeller. Curr Protoc Bioinformatics 2006; Chapter 5:Unit-5.6. https://doi.org/10.1002/cpbi.3
Fontana D, Kratje R, Etcheverrigaray M, Prieto C (2014) Rabies viruslike particles expressed in HEK293 cells. Vaccine 32:2799-2804. https://doi.org/10.1016/j.vaccine.2014.02.031

Fontana D, Kratje R, Etcheverrigaray M, Prieto C (2015) Immunogenic virus-like particles continuously expressed in mammalian cells as a veterinary rabies vaccine candidate. Vaccine 33:4238-4246. https://doi.org/10.1016/j.vaccine.2015.03.088

Fontana D, Marsili F, Garay E, Battagliotti J, Etcheverrigaray M, Kratje R, Prieto C (2019) A simplified roller bottle platform for the production of a new generation VLPs rabies vaccine for veterinary applications. Comp Immunol Microbiol Infect Dis 65:70-75. https://doi.org/10.1016/j.cimid.2019.04.009

Fontana D, Rodriguez MC, Garay E, Russo S, Prieto C (2020) Optimization and validation of a blocking ELISA for quantitation of anti-rabies immunoglobulins in multispecies sera. Appl Microbiol Biotechnol 104:4127-4139. https://doi.org/10.1007/ s00253-020-10490-6

Frietze KM, Peabody DS, Chackerian B (2016) Engineering virus-like particles as vaccine platforms. Curr Opin Virol 18:44-49. https:// doi.org/10.1016/j.coviro.2016.03.001

Gaudin Y, Ruigrok RW, Tuffereau C, Knossow M, Flamand A (1992) Rabies virus glycoprotein is a trimer. Virology 187:627-632. https://doi.org/10.1016/0042-6822(92)90465-2

Gedvilaite A, Frömmel C, Sasnauskas K, Micheel B, Özel M, Behrsing O, Staniulis J, Jandrig B, Scherneck S, Ulrich R (2000) Formation of immunogenic virus-like particles by inserting epitopes into surface-exposed regions of hamster polyomavirus major capsid protein. Virology 273:21-35. https://doi.org/10.1006/viro.2000. 0392

Gordon DM, McGovern TW, Krzych U, Cohen JC, Schneider I, LaChance R, Heppner DG, Yuan G, Hollingdale M, Slaoui M (1995) Safety, immunogenicity, and efficacy of a recombinantly produced Plasmodium falciparum circumsporozoite protein-hepatitis B surface antigen subunit vaccine. J Infect Dis 171:15761585. https://doi.org/10.1093/infdis/171.6.1576

Grgacic EVL, Anderson DA (2006) Virus-like particles: passport to immune recognition. Methods 40:60-65. https://doi.org/10.1016/j. ymeth.2006.07.018

Grubman M, Baxt B (2004) Foot-and-mouth disease. Clin Microbiol Rev 17:465-493. https://doi.org/10.1128/CMR.17.2.465

Hampson K, Coudeville L, Lembo T, Sambo M, Kieffer A, Attlan M, Barrat J, Blanton JD, Briggs DJ, Cleaveland S, Costa P, Freuling CM, Hiby E, Knopf L, Leanes F, Meslin FX, Metlin A, Miranda ME, Müller T, Nel LH, Recuenco S, Rupprecht CE, Schumacher C, Taylor L, Vigilato MAN, Zinsstag J, Dushoff J (2015) Estimating the global burden of endemic canine rabies. PLoS Negl Trop Dis 9:1-20. https://doi.org/10.1371/journal.pntd.0003709

Hu G, Wang N, Yu W, Wang Z, Zou Y, Zhang Y, Wang A, Deng Z, Yang Y (2016) Generation and immunogenicity of porcine circovirus type 2 chimeric virus-like particles displaying porcine reproductive and respiratory syndrome virus GP5 epitope B. Vaccine 34:1896-1903. https://doi.org/10.1016/j.vaccine.2016.02.047

Jallet C, Jacob Y, Bahloul C, Drings A, Desmezieres E, Tordo N, Perrin P (1999) Chimeric lyssavirus glycoproteins with increased immunological potential. J Virol 73:225-233. https://doi.org/10. 1128/JVI.73.1.225-233.1999

Jeong H, Seong BL (2017) Exploiting virus-like particles as innovative vaccines against emerging viral infections. J Microbiol 55:220 230. https://doi.org/10.1007/s12275-017-7058-3

Katz ISS, Guedes F, Fernandes ER, Dos Ramos Silva S (2017) Immunological aspects of rabies: a literature review. Arch Virol 1-18. https://doi.org/10.1007/s00705-017-3484-0

Li X, Meng X, Wang S, Li Z, Yang L, Tu L, Diao W, Yu C, Yu Y, Yan C, Wang L (2018) Virus-like particles of recombinant PCV2b carrying FMDV-VP1 epitopes induce both anti-PCV and anti-FMDV 
antibody responses. Appl Microbiol Biotechnol 102:1054110550. https://doi.org/10.1007/s00253-018-9361-2

Lua LHL, Connors NK, Sainsbury F, Chuan YP, Wibowo N, Middelberg APJ (2014) Bioengineering virus-like particles as vaccines. Biotechnol Bioeng 111:425-440. https://doi.org/10.1002/ bit.25159

Mahy BWJ (2005) Introduction and history of foot-and-mouth disease virus. Curr Top Microbiol Immunol 288:1-8. https://doi.org/10. 1007/3-540-27109-0_1

Mareze VA, Borio CS, Bilen MF, Fleith R, Mirazo S, Mansur DS, Arbiza J, Lozano ME, Bruña-Romero O (2016) Tests in mice of a dengue vaccine candidate made of chimeric Junin virus-like particles and conserved dengue virus envelope sequences. Appl Microbiol Biotechnol 100:125-133. https://doi.org/10.1007/ s00253-015-6973-7

McGinnes LW, Pantua H, Laliberte JP, Gravel KA, Jain S, Morrison TG (2010) Assembly and biological and immunological properties of Newcastle disease virus-like particles. J Virol 84:45134523. https://doi.org/10.1128/JVI.01931-09

Mohsen MO, Zha L, Cabral-Miranda G, Bachmann MF (2017) Major findings and recent advances in virus-like particle (VLP)-based vaccines. Semin Immunol 34:123-132. https://doi.org/10.1016/j. smim.2017.08.014

Naldini L, Blömer U, Gallay P, Ory D, Mulligan R, Gage FH, Verma IM, Trono D (1996) In vivo gene delivery and stable transduction of nondividing cells by a lentiviral vector. Science 272:263-267. https://doi.org/10.1126/science.272.5259.263

Pettersen EF, Goddard TD, Huang CC, Couch GS, Greenblatt DM, Meng EC, Ferrin TE (2004) UCSF Chimera - a visualization system for exploratory research and analysis. J Comput Chem 25:1605-1612. https://doi.org/10.1002/jcc.20084

Pijlman GP (2015) Enveloped virus-like particles as vaccines against pathogenic arboviruses. Biotechnol J 10:659-670. https://doi.org/ 10.1002/biot.201400427

Prieto C, Fontana D, Etcheverrigaray M, Kratje R (2011) A strategy to obtain recombinant cell lines with high expression levels. Lentiviral Vector-Mediated Transgenesis. BMC Proc 5(Suppl 8):P7. https://doi.org/10.1186/1753-6561-5-S8-P7

Raghunandan R (2011) Virus-like particles: innate immune stimulators. Expert Rev Vaccines 10:409-411. https://doi.org/10.1586/ erv.11.37

Ramasamy V, Arora U, Shukla R, Poddar A, Shanmugam RK, White LJ, Mattocks MM, Raut R, Perween A, Tyagi P, de Silva AM, Bhaumik SK, Kaja MK, Villinger F, Ahmed R, Johnston RE, Swaminathan S, Khanna N (2018) A tetravalent virus-like particle vaccine designed to display domain III of dengue envelope proteins induces multi-serotype neutralizing antibodies in mice and macaques which confer protection against antibody dependent enhancement in AG129 mice. PLoS Negl Trop Dis 12:e0006191. https://doi.org/10.1371/journal.pntd.0006191

Roche S, Gaudin Y (2002) Characterization of the equilibrium between the native and fusion-inactive conformation of rabies virus glycoprotein indicates that the fusion complex is made of several trimers. Virology 297:128-135. https://doi.org/10.1006/viro.2002. 1429
Roche S, Rey FA, Gaudin Y, Bressanelli S (2007) Structure of the Prefusion Form of VSV G. Science (80-) 315:843-848. https:// doi.org/10.1126/science.1135710

Roldão A, Mellado MCM, Castilho LR, Carrondo MJT, Alves PM (2010) Virus-like particles in vaccine development. Expert Rev Vaccines 9:1149-1176. https://doi.org/10.1586/erv.10.115

RTS SCTP (2015) Efficacy and safety of RTS, S/AS01 malaria vaccine with or without a booster dose in infants and children in Africa: final results of a phase 3, individually randomised, controlled trial. Lancet 386:31-45. https://doi.org/10.1016/S0140-6736(15) 60721-8

Schindelin J, Arganda-Carreras I, Frise E, Kaynig V, Longair M, Pietzsch T, Preibisch S, Rueden C, Saalfeld S, Schmid B, Tinevez JY, White DJ, Hartenstein V, Eliceiri K, Tomancak P, Cardona A (2012) Fiji: An open-source platform for biological-image analysis. Nat Methods 9:676-682. https://doi.org/10.1038/nmeth.2019

Sievers F, Wilm A, Dineen D, Gibson TJ, Karplus K, Li W, Lopez R, McWilliam H, Remmert M, Söding J, Thompson JD, Higgins DG (2011) Fast, scalable generation of high-quality protein multiple sequence alignments using Clustal Omega. Mol Syst Biol 7:539. https://doi.org/10.1038/msb.2011.75

Vicente T, Roldão A, Peixoto C, Carrondo MJT, Alves PM (2011) Large-scale production and purification of VLP-based vaccines. J Invertebr Pathol 107:S42-S48. https://doi.org/10.1016/j.jip.2011. 05.004

Vietheer PTK, Boo I, Drummer HE, Netter HJ (2007) Immunizations with chimeric hepatitis B virus-like particles to induce potential anti-hepatitis $\mathrm{C}$ virus neutralizing antibodies. Antivir Ther $12: 477-487$

Votteler J, Sundquist WI (2013) Virus budding and the ESCRT pathway. Cell Host Microbe 14:232-241. https://doi.org/10.1016/j. chom.2013.08.012

Waterhouse AM, Procter JB, Martin DMA, Clamp M, Barton GJ (2009) Jalview Version 2-a multiple sequence alignment editor and analysis workbench. Bioinformatics 25:1189-1191. https:// doi.org/10.1093/bioinformatics/btp033

World Health Organization (2018) WHO Expert Consultation on rabies. WHO Technical Report Series No. 1012

Xu L, He D, Yang L, Li Z, Ye X, Yu H, Zhao H, Li S, Yuan L, Qian H, Que Y, Kuo Shih JW, Zhu H, Li Y, Cheng T, Xia N (2015) A broadly cross-protective vaccine presenting the neighboring epitopes within the VP1 GH loop and VP2 EF loop of enterovirus 71. Sci Rep 5:12973. https://doi.org/10.1038/srep12973

Yan D, Wei Y-Q, Guo H-C, Sun S-Q (2015) The application of virus-like particles as vaccines and biological vehicles. Appl Microbiol Biotechnol 10415-10432. https://doi.org/10.1007/ s00253-015-7000-8

Zhang YL, Guo YJ, Wang KY, Lu K, Li K, Zhu Y, Sun SH (2007) Enhanced immunogenicity of modified hepatitis B virus core particle fused with multiepitopes of foot-and-mouth disease virus. Scand J Immunol 65:320-328. https://doi.org/10.1111/j.13653083.2007.01900.x

Publisher's note Springer Nature remains neutral with regard to jurisdictional claims in published maps and institutional affiliations. 